LBNL-46038, Published in Energy and Buildings 33 (8) (2001), pp. 783-791.

\author{
Analysis of an Information Monitoring and Diagnostic System \\ to Improve Building Operations \\ Mary Ann Piette, Satkartar Kinney, and Philip Haves \\ Lawrence Berkeley National Laboratory, Berkeley, CA, USA
}

\begin{abstract}
This paper discusses a demonstration of a technology to address the problem that buildings do not perform as well as anticipated during design. We partnered with an innovative building operator to evaluate a prototype Information Monitoring and Diagnostic System (IMDS). The IMDS consists of a set of high-quality sensors, data acquisition software and hardware, and data visualization software, including a webbased remote access system, that can be used to identify control problems and equipment faults. The information system allowed the operators to make more effective use of the building control system, freeing up time to take care of other tenant needs. They report observing significant improvements in building comfort, potentially improving tenant health and productivity. The reduction in the labor costs to operate the building is about $\$ 20,000$ per year, which alone could pay for the information system in about five years. A control system retrofit based on findings from the information system is expected to reduce energy use by 20 percent over the next year, worth over $\$ 30,000$ per year in energy cost savings. The operators are recommending that similar technology be adopted in other buildings.
\end{abstract}

\title{
Background
}

Buildings rarely perform as well in practice as anticipated during design. There are many reasons for this, including improper equipment selection and installation, lack of rigorous commissioning and proper maintenance, and poor feedback on operational performance, including energy performance. A recent evaluation of new construction commissioning found that 81 percent of the building owners surveyed encountered problems with new heating and air conditioning systems [1]. Another study of 60 buildings found that half were experiencing controls problems, 40 percent had HVAC equipment problems, 15 percent had missing equipment, and 25 percent had Energy Management Control Systems (EMCS), economizers, and/or variable speed drives that were not functioning properly [2]. Such problems are widely reported in the building commissioning literature [3].

Systematic procedures to address these problems are beginning to emerge. For example, research at Texas A\&M University has found that in almost all older buildings, and even in many new buildings, the use of the building is quite different from the original plan [4]. These researchers use a monitoring process of "continuous commissioning" to tune building systems for optimal comfort and peak efficiency based on current operational requirements. Their methods have saved an average of over 20 percent of the total energy cost (over 30 percent of the heating and cooling cost) in over 80 buildings. While these researchers have demonstrated success by bringing in experts to "fix" building systems, few tools are available to the on-site engineer to conduct such improvements. 
A related problem is that EMCSs are becoming more complex over time and are difficult for the average operator to understand [5]. Furthermore, most EMCSs do not include energy monitoring in their scope and are limited in collecting, archiving, and displaying important building performance data.

Most building operators have only the monthly utility bill to track how energy is used. One study that supplied building operators with energy use data found that after a few months of strong enthusiasm, building operators lost interest in standard energy use plots provided by the utility research project [6]. Building operators need assistance in extracting useful information from the large volume of data produced by new monitoring technologies.

\section{Project Objectives and Approach}

The broad goal of this multi-year, multi-institutional project was to develop, introduce, and evaluate state-of-the-art information technology, enhance building energy performance by continuously improving operations and maintenance (O\&M). This project involved both market assessment and intervention activities to accelerate the adoption of advanced information technology. By advancing state-of-the-art information technology, we hope to help push the market toward greater overall performance. The research team analyzed the decision-making processes used by building operations staff to understand what motivates them to accept or reject new technology. The work is intended to facilitate future market-pull initiatives based on an understanding of these decision-making criteria. A final technical goal is to develop strategies that advance the technology from passive monitoring systems to automated diagnostic systems, taking advantage of emerging computational and modeling capabilities.

This paper presents a summary of the overall concept and findings from the use of a sophisticated Information Monitoring and Diagnostic System (IMDS) in a commercial office building in San Francisco. The paper is summary of a larger report [7]. Two companion papers describe additional elements of the project. Haves and Khalsa [8] review automated fault detection methods in general, and present a specific case study of chiller modeling at the IMDS test site. Shockman and Piette [9] summarize results from the analysis of the decision-making processes and technology innovation and adoption issues relating to the IMDS.

This project was carried out in three phases. Phase One, conducted during the mid1990s, included an investigation and evaluation of diagnostic methods, tools, and techniques [10]. The analysis considered issues such as sensor and communications technology, bottom-up versus top-down diagnostics architecture, and the design of temporary versus permanent systems. We examined the status of techniques from the field of intelligent systems (e.g., artificial intelligence, fuzzy logic, and neural networks) and diagnostics used in process control industries. We identified innovative building operators and chief engineers in major metropolitan areas who were recruited to give the research team direct feedback on what they thought were the most serious problems in commercial buildings operations. The interviews concluded that there was no single outstanding problem that would define the priority area for diagnostics research. Rather, there is a set of related problems that include a lack of good information about the performance of their buildings overall, in particular, a lack of good information from the EMCSs. 
During Phase Two, the operations staff and the office building were selected for a case study, and the system design was finalized and installed. The building engineer-operator selected for the case study is known among his peers as a technology innovator. He is a technology manager for a third-party property management company, and is responsible for more than one hundred buildings in the Western United States. A review of the building energy use and initial findings from the IMDS during Phase Two are reported in Piette et al. [11]. The IMDS began monitoring in May 1998. The building staff began using the system on a daily basis in late Summer 1998.

The third phase of the research project began with the commissioning of the monitoring system. Data quality was evaluated on a regular basis and building staff were interviewed biweekly to determine how the IMDS was used A detailed analysis of the building's historical energy use was conducted to determine if any energy savings were achieved during the project time period. A specification for the IMDS is available to the public on the World Wide Web [12]. A set of 57 points (described in the following section) was monitored from May 1998 through December 1999.

\section{IMDS Characteristics}

The IMDS consists of a set of high-quality sensors, data acquisition software and hardware, and data visualization software, including a web-based remote access system. The IMDS is a prototype system in that a unique combination of sensors, hardware, and software has been deployed in a controlled test to examine its value. The system can be built up from individual components and installed in any commercial building. It is, however, a high-end system, intentionally designed for high reliability, accuracy, and speed in data acquisition, archiving and retrieval.

The IMDS is oriented toward deploying the basic infrastructure for an advanced information system. This demonstration will allow the controls industry to examine the value of such systems that greatly exceed today's current EMCS technology. The IMDS is intended to be a suitable platform for more advanced, automated, model-based or knowledge-based diagnostic systems. The primary elements of the system, as installed in this project, are:

- A monitoring and data acquisition system that records 57 measured and 28 calculated points obtained from high-quality sensors, including points typically not available from an EMCS

- A PC that stores the data, runs the data visualization software and provides the onsite staff with direct access to the data.

- A web server hosting a real-time visualization and analysis tool that has a subset of the data visualization capabilities of the on-site system

The data visualization software, known as Electric Eye [13], was originally developed for use with a high-end graphical workstation and now runs on PCs using the Linux operating system. The software is quite powerful, allowing one to examine large data sets. It is possible to manipulate and display more than a year of one-minute data from up to eight points simultaneously.

The IMDS development in Phase One included creating nine standard plots available for viewing of key performance data. The operations staff was trained to interpret these plots. The IMDS also offers a series of more sophisticated browsing and statistical 
analysis tools, some of which may be of greater use to engineers and researchers. The PC server offers a subset of the real-time analysis graphics from the demonstration site to the public over the World Wide Web. The purpose of these graphs is to demonstrate the technology to interested organizations and potential service providers such as energy service companies, utilities, and control companies.

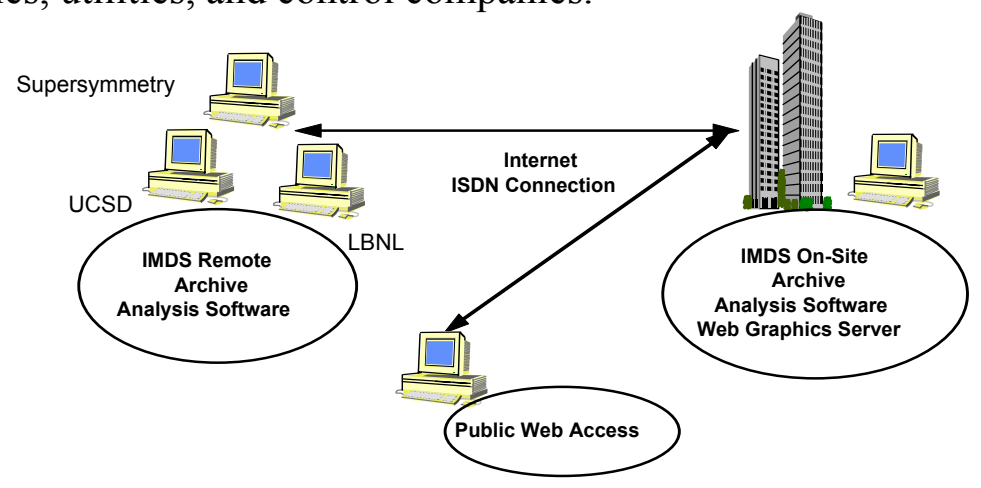

Figure 1. Components of the Information and Monitoring Diagnostics System. LBNL, UC San Diego, and Supersymmetry USA all received and reviewed data from the IMDS.

Four types of measurements are taken by the IMDS: temperature (including wet-bulb), electric power, flow rate, and pressure. The sensors include high quality thermistors, electric power transducers, magnetic flow meters and aspirated psychrometers. Table 1 summarizes the scope of the monitoring. Further details of the sensors and sensor accuracy are presented in Piette et al. [11]. There were only three points from the IMDS that were also available from the EMCS: outside air, supply air, and return air temperatures. 
Table 1. Systems and sensors in the IMDS

\begin{tabular}{|l|l|c|}
\hline \multicolumn{1}{|c|}{ System to be evaluated } & \multicolumn{1}{|c|}{ Measurement } & \multicolumn{1}{c|}{$\begin{array}{c}\text { Number of } \\
\text { physical points }\end{array}$} \\
\hline Whole building & Electric power & 1 \\
\hline Two chillers & Differential pressure (water) & 4 \\
& Water temperatures & 8 \\
& Flow rates (water) & 5 \\
& Electric power & 2 \\
\hline Four pumps & Differential pressure (water) & 4 \\
& Electric power & 4 \\
\hline One cooling tower & Drybulb temperature & 2 \\
& Wetbulb temperature & 2 \\
& Water temperatures & 6 \\
& Electric power & 2 \\
\hline One air handler & Drybulb temperatures & 5 \\
& Electric power & 2 \\
& Static pressure & 4 \\
\hline Local micro-climate & Drybulb temperature & 1 \\
& Wetbulb temperature & 4 \\
\hline Miscellaneous (lights \& plug) & Electric power & 57 \\
\hline Total & \multicolumn{2}{|l}{} \\
\hline
\end{tabular}

The IMDS is designed to be permanently installed and continuously active. This is necessary because buildings continuously change. For example, some problems recur, such as those from modifications to schedules to handle special events. These modifications often lead to equipment being left on when not needed. The diagnostic system is designed to operate in parallel with an existing EMCS, rather than expanding or modifying the EMCS. The IMDS is therefore not constrained by current EMCS data collection capabilities, which are often inadequate to handle one-minute data for a significant number of points. Many of the most significant features may, however, be incorporated in future EMCS. The EMCS at the demonstration site provides scheduling and control of the HVAC systems including air temperatures and flows. By contrast, in this installation, the IMDS measures energy, weather and water-side variables (temperatures, pressures, and flows).

\section{Results}

There have been three primary benefits of the IMDS at the pilot demonstration site in San Francisco:

1. A dramatic improvement in the operators' understanding and use of the existing control system, resulting in greater automation of the controls and a control redesign which is expected achieve significant energy savings in the future.

2. A reduction in complaint calls and improved comfort, which increases tenant satisfaction and productivity. 
3. Extended equipment life, both from reduced short cycling, which is a result of the improved control, and from detection and removal of air in the chilled water system.

The results of the bi-weekly interviews showed that theoperators perceive significant improvements in the performance of the building as a result of the IMDS. These include improvements in control, reduced comfort complaints, and the identification of significant energy savings. The IMDS has been useful in identifying operational problems that are a result of inherent limitations of the control system itself. These particular problems can only be remedied with an EMCS retrofit, which is planned for 2001. The IMDS has played a major role in identifying the requirements for the retrofit. The new EMCS will be required to perform functions similar to those of the IMDS. The following are features requested by the technical manager for the new control system: 1. Abandonment of the "trend log" metaphor, replacing it with a "data archive." 2. A graphical interface that is not a picture of a fan or chiller system with current readings attached, but is, instead, an $x-y$ graph of current and previous system data; the data to be selected "on-the-fly" by the operator.

3. Remote system access by any web browser, as opposed to dial-up software supplied by the vendor, or general-purpose software that provide remote control of the supervisor PC.

There have not been significant energy savings to date. While the 15 percent savings objective has not yet been achieved, more than 15 percent in savings could be achieved if the controls were properly functioning. In particular, the operations staff estimates they could reduce steam use by 50\% with improved control and a valve retrofit (Table 2). They also expect chiller plant energy savings from reduced reheat. The original estimate from the operations staff was that the reduction in steam use would be similar in magnitude to chiller savings. This estimate is approximately equivalent to the current chiller energy use based on a COP of 3.5. A more conservative savings estimate is approximately a quarter of current chiller energy use. The largest electricity savings, however, are likely to come from a reduction in fan energy consumption. Correcting a fan control problem found using the IMDS that relates to the variable frequency drives is expected to save $122 \mathrm{MWh} /$ year. The fan power data showed that the supply fan ran at full power and never modulated as expected with a VFD. Part of the problem with the VFD turned out to be related to a faulty supply duct pressure sensor located in an area with asbestos.

Table 2. Predicted savings from the proposed control retrofit

\begin{tabular}{|l|l|l|l|}
\hline & $\begin{array}{l}\text { Current EUI } \\
\left(\mathbf{M J} / \mathbf{m}^{2} \mathbf{- y r}\right)\end{array}$ & $\begin{array}{l}\text { Predicted Savings } \\
(\mathbf{\%})\end{array}$ & $\begin{array}{l}\text { Savings } \\
\left(\mathbf{M J} / \mathbf{m}^{2}-\mathbf{y r}\right)\end{array}$ \\
\hline Steam & 419 & 50 & 210 \\
\hline Electricity & 631 & 8 & 52 \\
\hline Total & 1050 & 25 & 262 \\
\hline
\end{tabular}

Note: Energy Use Intensity (EUI) is based on 8550 square meters of net rentable floor space. Total gross floor space is 9290 square meters. 
The remote monitoring capability proved to be highly useful to the operations staff. The technical manager would log onto the web-based data visualization tool early in the morning to examine the morning warm-up temperatures at the building. He would check it several times before coming into the office. Once arriving, he would use the more sophisticated data analysis tool (Electric Eye). Over time, the operations staff implemented a series of changes in the control strategies. Figures 2 and 3 show typical days before and after modifications to the supply air control, respectively. Figure 2 shows the supply air temperature oscillating throughout the morning, demonstrating the inability to provide stable control. Such oscillations can make it difficult to maintain comfort conditions The improved control performance obtained by retuning the control loop is illustrated in Figure 3.

The supply air intake temperature is shown on Figures 2 and 3 because it was the source of an interesting lesson concerning outside air measurements. The researchers installed a sensor located in the supply air duct intake area near the EMCS sensor labeled "outside air temperature". However, when the fans are off at night, heat rises through the building and the sensor measures the temperature increase. The sensor does not provide a good measure of outside air temperature. This is particularly problematic if one were to use average daily temperature values in an energy analysis or related use of off-hour outside temperature data. The research team had to move the outside weather station several times to find a good location without shade or other complications.

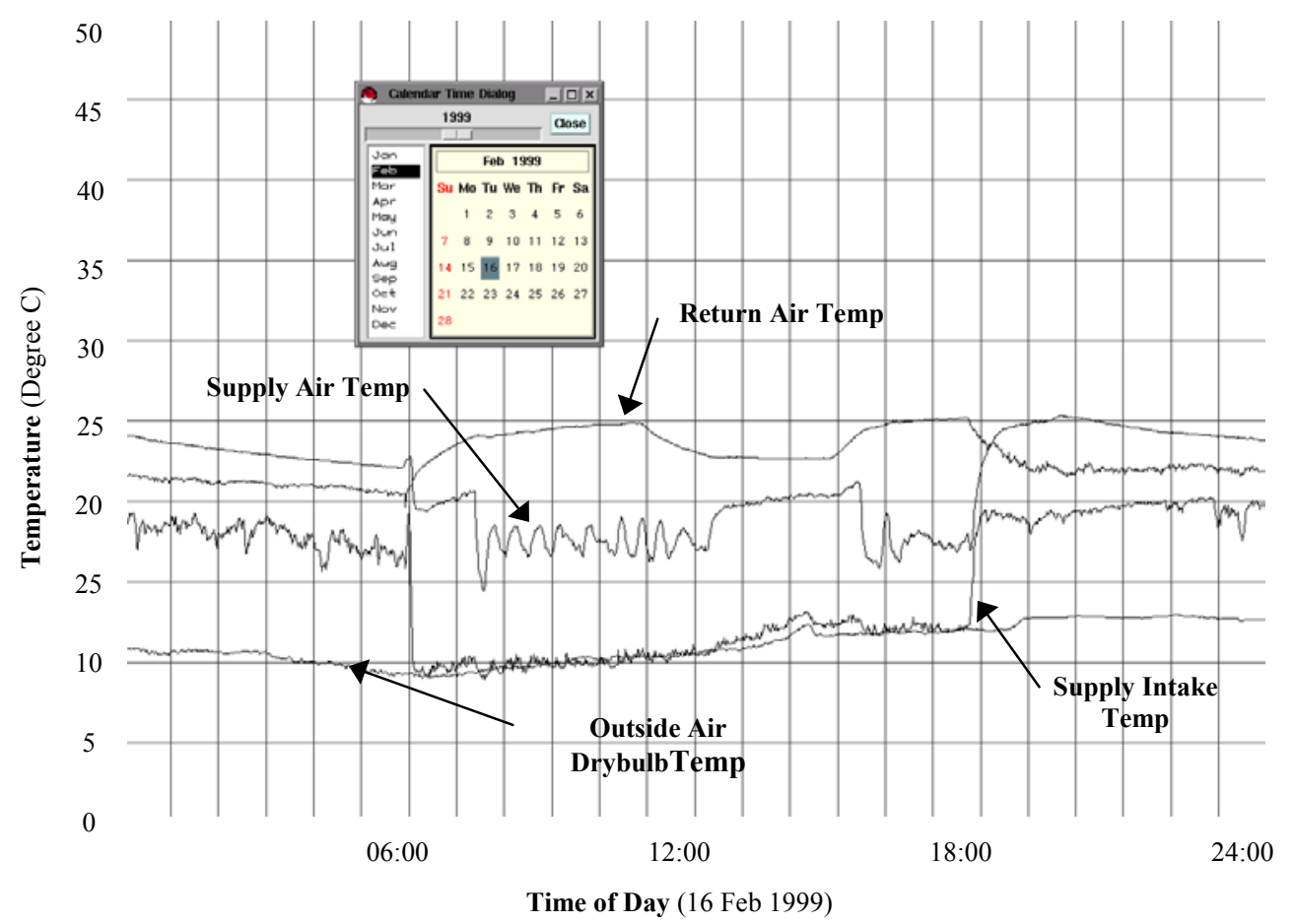

Figure 2. Supply air with poor control 




Figure 3. Supply air with improved control

Table 3 lists the seven most significant problems identified and remedied in 19981999, including the measurements used, the required resolution, and the primary benefits of the correction. The most significant correction has been the adjustments to the morning warm-up and supply air control. Prior to the deployment of the IMDS, the operators had little feedback on the performance of the HVAC equipment. As a result of faulty programming of the EMCS, the supply air was actually being controlled from the return air temperature. Only after several months of careful examination of IMDS data did the operations staff begin to understand how the controls actually functioned. While this may seem surprising, it is actually fairly common within the buildings industry that building engineers defeat and work around control systems that they do not understand. There were no drawings or descriptions of the control logic explaining how the controls are intended to operate. 
Table 3. Problems identified and remedied with IMDS

\begin{tabular}{|c|c|c|c|c|}
\hline $\begin{array}{l}\text { Problem } \\
\text { type/description }\end{array}$ & $\begin{array}{l}\text { Date } \\
\text { Discovered } \\
\text { \& Fixed }\end{array}$ & Which data used & $\begin{array}{l}\text { Resolution } \\
\text { needed }\end{array}$ & Benefits \\
\hline $\begin{array}{l}\text { Control/Chiller } \\
\text { false-start correction }\end{array}$ & $\begin{array}{l}\text { D: } 2 \text { May } 98 \\
\text { F: Over year }\end{array}$ & $\begin{array}{l}\text { Chiller Power, } \\
\text { Cooling Load, Cooling } \\
\text { Plant Power }\end{array}$ & 1 minute & $\begin{array}{l}\text { Avoiding unloaded } \\
\text { operation, which could } \\
\text { cause major chiller } \\
\text { failure }\end{array}$ \\
\hline O\&M/Air in pipes & $\begin{array}{l}\text { D: } 1 \text { Sep } 98 \\
\text { F: } 10 \text { Sep } 98\end{array}$ & Flows, Cooling Load & 15 minute & $\begin{array}{l}\text { Flow changed from } \\
0.02 \mathrm{~m}^{3} / \mathrm{s} \text { to } 0.04 \mathrm{~m}^{3} / \mathrm{s} \\
\text { for Chiller Two, coils } \\
\text { not starved now, } \\
\text { improved pump life }\end{array}$ \\
\hline $\begin{array}{l}\text { Desgin/Exhaust air } \\
\text { re-circulating to } \\
\text { towers }\end{array}$ & $\begin{array}{l}\text { D: } 16 \text { Nov } 98 \\
\text { F: } 16 \text { Nov } 98\end{array}$ & $\begin{array}{l}\text { Return Air, Tower } \\
\text { Dry-Bulb Temp }\end{array}$ & 15 minute & $\begin{array}{l}\text { Improved tower } \\
\text { efficiency }\end{array}$ \\
\hline $\begin{array}{l}\text { Control/Morning } \\
\text { warm-up tuning }\end{array}$ & $\begin{array}{l}\text { D: Jan } 99 \\
\text { F: Mar } 99\end{array}$ & $\begin{array}{l}\text { Supply, Mixed, Return } \\
\text { Air Temp, Outside Air } \\
\text { Temp. }\end{array}$ & 1 minute & $\begin{array}{l}\text { Extended actuator life, } \\
\text { improved comfort }\end{array}$ \\
\hline $\begin{array}{l}\text { Control/Supply air } \\
\text { tuning }\end{array}$ & $\begin{array}{l}\text { D: Jan } 99 \\
\text { F. Jun } 99\end{array}$ & $\begin{array}{l}\text { Supply, Mixed, Return } \\
\text { Air Temp }\end{array}$ & 1 minute & $\begin{array}{l}\text { Extended actuator life, } \\
\text { improved comfort }\end{array}$ \\
\hline $\begin{array}{l}\text { O\&M/Fan power } \\
\text { oscillations* }\end{array}$ & $\begin{array}{l}\text { D: Feb } 99 \\
\text { F: Mar } 99\end{array}$ & $\begin{array}{l}\text { Supply \& Return Fan } \\
\text { kW, Supply Air Temp }\end{array}$ & $\begin{array}{l}1 \text { second \& } 1 \\
\text { minute }\end{array}$ & $\begin{array}{l}\text { Extended fan life, } \\
\text { improved control and } \\
\text { comfort }\end{array}$ \\
\hline $\begin{array}{l}\text { Control/Unnecessary } \\
\text { dual-pump operation }\end{array}$ & $\begin{array}{l}\text { D: Oct } 98 \\
\text { F: Mar } 99\end{array}$ & $\begin{array}{l}\text { Pump Power, Chiller } \\
\text { Power and Cooling } \\
\text { Load }\end{array}$ & 15 minute & $\begin{array}{l}\text { Reduced energy use, } \\
\text { extended pump life }\end{array}$ \\
\hline
\end{tabular}

*Corrected by tightening fan belt

One result of the control improvements has been a reduction in complaint calls. The building operator initially reported that complaint calls had been reduced from twenty to three per month. This claim was investigated by studying the complaints logged between December 1998 and May 1999. The data showed that the number of complaints varied from three to 21 per month. We did not identify the reduction that was reported by the on-site staff. We were later informed that not all complaints are logged, but the operations staff felt that the reduction did take place. Although we do not have concrete evidence from the complaint logs, the building management staff is confident that complaints have been significantly reduced.

It became clear in the course of monitoring that there are significant problems with the chilled water plant controls. The chillers often operate for short periods of time, cycling too frequently, and the cooling tower controller is often unstable. This is one of the findings motivating the controls retrofit.

As mentioned, in addition to the energy savings opportunities identified, the IMDS has been used to improve the use of the existing controls. The operations staff estimates that the operator spends significantly less time operating the building because the current system is now as fully automated as possible. The IMDS has freed up time to provide other services to the building tenants. The staff estimates a reduction in labor-hours of about 20 percent, equivalent to about to about 416 hours per year, or about $\$ 20,000$ per year. The operations staff can pursue other activities that provide value to the building, including billable tenant services. One significant activity that has occurred as a result of 
the additional time for operations and maintenance is balancing of the air system. The operations staff has balanced the air flow on each floor, which has contributed to the improved comfort and decrease in complaint calls. This $\$ 20,000$ per year savings from the IMDS is equivalent to a five-year payback on O\&M savings independent of the forthcoming expected future energy savings. Furthermore, comfort improvements may have significant effects on the productivity and health of office workers in the building [13].

The importance of sensor accuracy is related to the use of the data. The data have been most directly valuable to the operations staff in tracking and evaluating how the controls function. Most of the problems identified and remedied by the operations staff could have been diagnosed using lower-quality sensors. Identifying most of the problems did require the high-frequency (one-minute) data. Piette, et al. [11] provides a detailed discussion of the IMDS sensor and calculated point measurement accuracies for full and part load conditions.

Figure 4 shows a problem with chiller cycling that would not have been detected without one-minute data. The problem occurred after a service technician made some modifications to the chiller inlet vane control. Figure 5 shows the same data using 15minute average data. The building operator believed this graph represented normal operation. He further commented that he would have found the cycling problem the next day but that would have been too long, given the severity of the cycling.

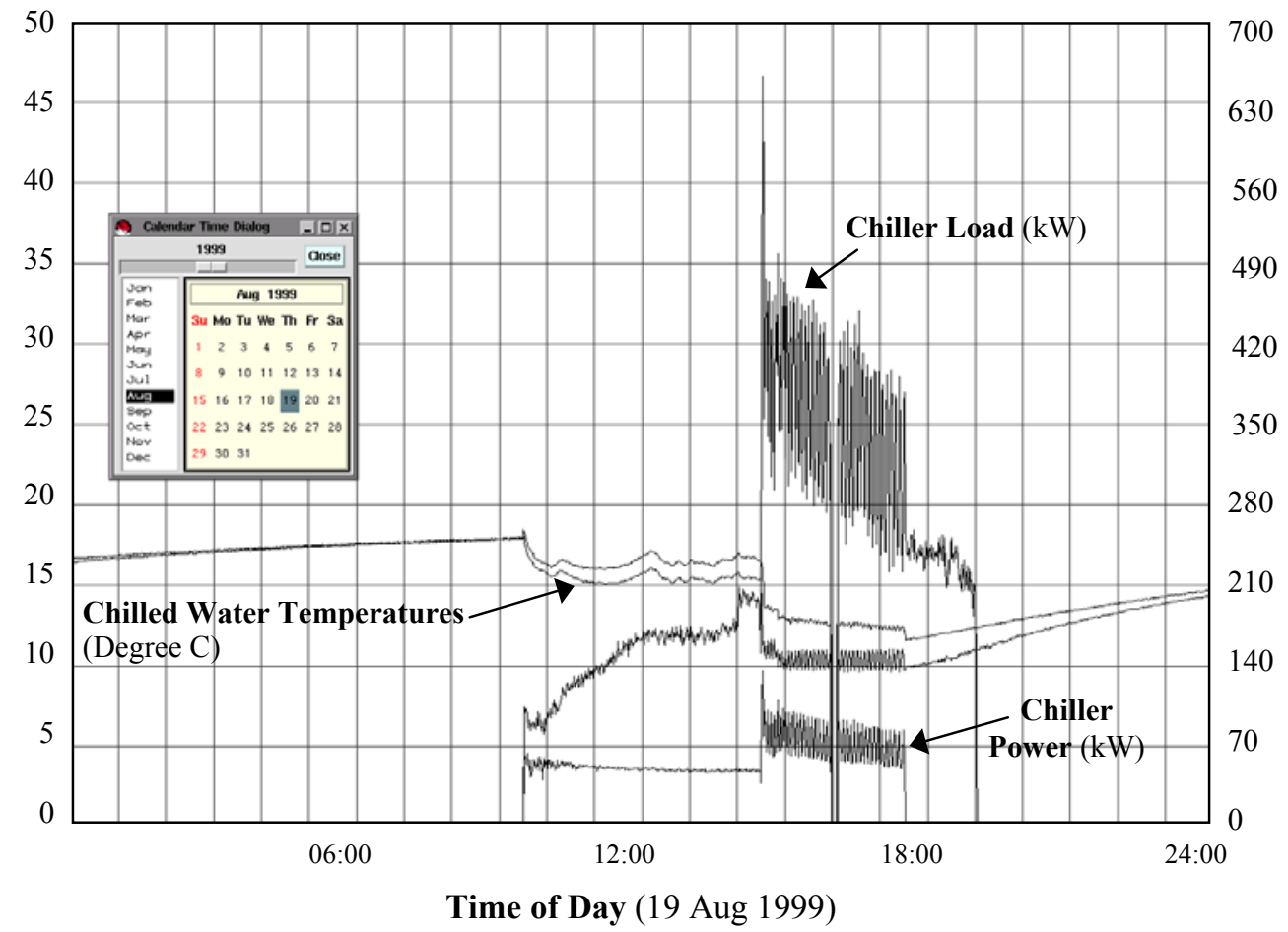

Figure 4. Oscillations viewed with 1-minute data. The chiller load is the thermal load, or duty, on the chiller, shown in $\mathrm{kW}$. The chiller electric power ( $\mathrm{kW}$ as well) is also shown. 


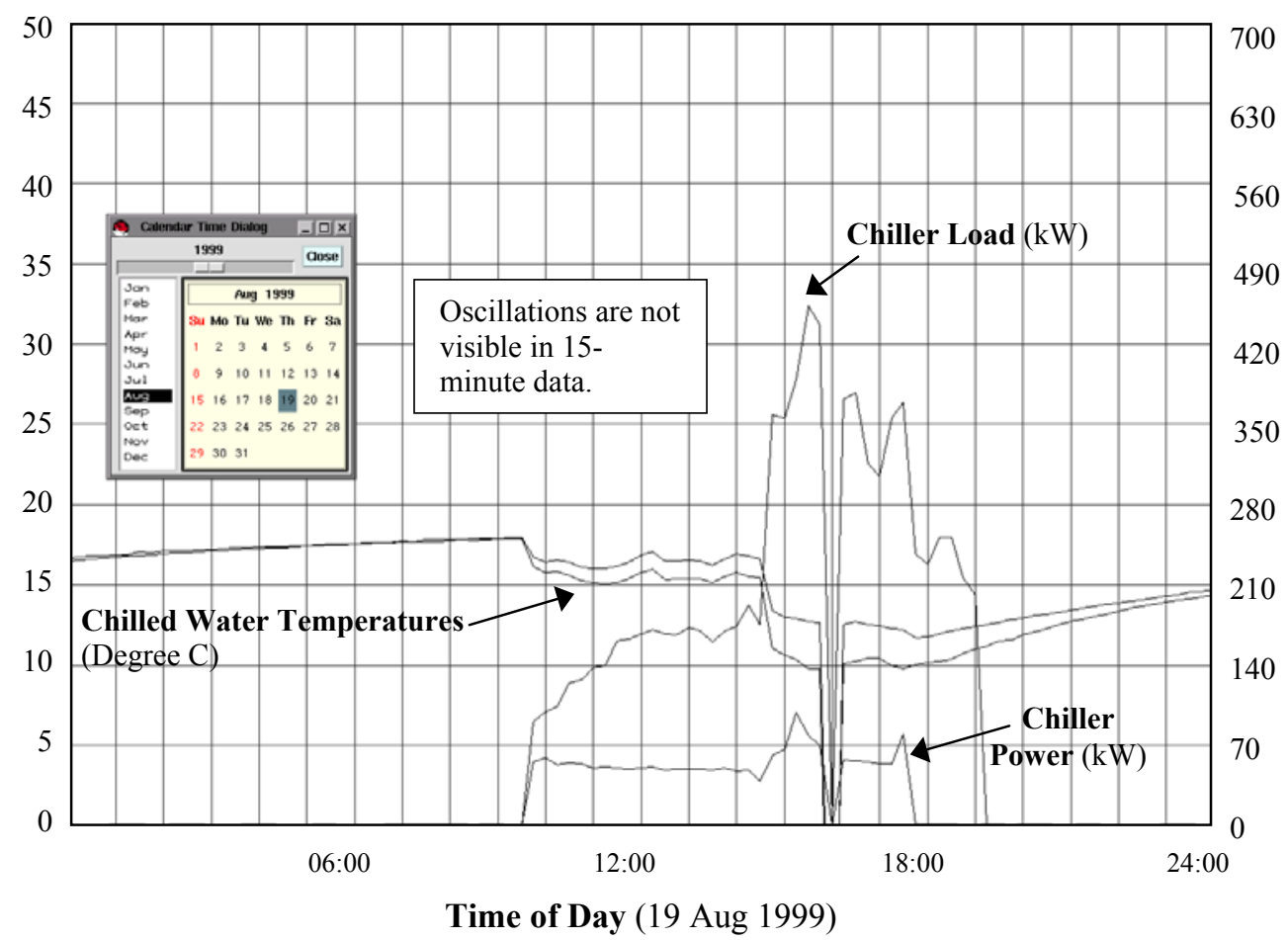

Figure 5. Oscillations not apparent using 15-minute data

\section{Economic and Market Potential}

During Phase Two, the IMDS was installed for about $\$ 63,000$, including hardware, software, and one year of ISDN service (Table 4). The cost of the installation of the sensors on the site was self-reported by the building staff at around $\$ 24,000$. We believe the managers at the building have paid for some of the costs by "bolting the costs" on to other items, and installation costs were actually higher. If sensor installation costs are conservatively assumed to be 50 percent of the hardware and software cost, the results is a total cost for hardware, software, and installation of about one dollar per square foot.

Table 4. Information Monitoring and Diagnostic System prototype costs

\begin{tabular}{|l|l|}
\hline System & Cost \\
\hline Data acquisition system $\left(\right.$ EnFlex $\left.^{(B)}\right)$ & $\$ 8,535$ \\
\hline Computer system & $\$ 3,938$ \\
\hline Sensors & \\
\hline \multicolumn{1}{|c|}{ Cooling system } & $\$ 31,860$ \\
\hline Air handlers & $\$ 5,784$ \\
\hline \multicolumn{1}{|c|}{ Building power } & $\$ 3,916$ \\
\hline \multicolumn{1}{|c|}{ Sensor Total } & $\$ 41,560$ \\
\hline Networking (ISP and 1 year of ISDN) & $\$ 8,912$ \\
\hline Grand Total & $\$ 62,945$ \\
\hline
\end{tabular}

The on-site staff has shown great interest in the overall system, but are not inclined to support the use of the high quality sensors used in the demonstration. They do, however, value the power and flow rate measurements available from the system, which are rarely 
available from an EMCS. Power measurements from dynamic systems, such as fans, chillers, cooling towers, plug loads, and lighting loads are of particular interest. The remote access, data archival capabilities, and high quality visualization tools are also features of significant value to the operations staff. The cost of each point in the prototype IMDS installation can be found in the online specification [12]. There are a number of good opportunities to bring the system cost down and these will be pursued in a follow-on project described in the Future Work section below. For example, it is likely that any future IMDS would not use the temperature sensor calibration procedure that cost about $\$ 350$ per thermistor.

The operations staff estimates that they will save approximately $\$ 45,000$ per year in energy costs as a result of the control system retrofit planned for 2001. This is based on reducing steam use by about half (worth $\sim \$ 25,000$ per year), reducing chiller energy use by about $38 \mathrm{MWh}$ per year and reducing fan energy use by about $122 \mathrm{MWh}$ per year. Overall, the system is likely to payback over the next few years if the controls retrofit is complete and the savings from the fan variable frequency drive and the steam are realized. The IMDS has not yet shown a payback based on energy savings. It has demonstrated that the technology is of value, plus the staff wants to continue to purchase and use such technology in other buildings.

This technology has demonstrated its value, although it is likely to be expensive in its current form. As mentioned above, the on-site staff is extremely interested in remote, web-based data archival and visualization tools. Several dozen commercial buildings industry representatives have toured the last year, including software developers, energy service companies, utilities, and researchers. There are a variety of building monitoring technology development activities that are being influenced by this demonstration. Control companies were not asked to participate directly in this project as that participation might have constrained the project because of inherent biases that building operators have toward various control systems. However, the controls industry and other potential building information technology service providers are part of the target audience for this technology.

While the energy savings potential of IMDS-type technology is significant, this technology is likely to be adopted for non-energy benefits as well as energy-savings benefits. This demonstration has shown that comfort is enhanced with IMDS-type technology. This could have far reaching affects on office workers, increasing productivity and health [14]. Improvements in equipment life and reduced maintenance costs are likely as well.

\section{Conclusions and Future Work}

This research project has found the IMDS to be of significant value to building operators at a demonstration site. The operators invested significant time to learn how to work with the data sets and visualization tools that the research team provided. This investment in time paid back in that they greatly improved their knowledge about how the control and HVAC systems actually operated.

Discussions are underway with the present operations staff and other building operations staff to demonstrate these concepts in other buildings. We are currently installing a second IMDS in Sacramento, California. This site will allow us to more directly compare newer, state-of-the-art EMCS with the IMDS. Such demonstrations 
will help identify how universal are the findings from the pilot implementation described here, considering diverse factors such as the building operations staff, climates, and HVAC system variations. The future work will also include investigation of the performance of model-based fault detection methods for HVAC systems

Tracking of the operation of the IMDS at the pilot demonstration site will continue in order to examine persistence of use and energy savings from the forthcoming control retrofit. After a series of bids were evaluated, the current IMDS technology suite was selected to serve as the platform for the new control system. This will allow the collection and evaluation of more detailed control and operational data and the deployment and testing model-based fault detection technology.

\section{Acknowledgments}

Additional members of the research team included Peter Rumsey, Kristopher Kinney (formerly of Supersymmetry, now with Engineered Web Information Systems), Christine Shockman (Stanford University), and Anthony Sebald (UC San Diego). Special thanks to Lee Eng Lock (Supersymmetry), who pioneered many of the concepts in this research. We greatly appreciate the support from the California Energy Commission, and feedback from Project Manager, Joseph Wang. We also appreciate the support from the California Institute for Energy Efficiency. Publication of research results does not imply CIEE endorsement or agreement with these findings, nor that of any CIEE sponsor. Previous phases of the work were also funded by the U.S. Department of Energy Assistant Secretary for Energy Efficiency and Renewable Energy, Office of Building Technology, State and Community Programs under Contract No.DE-AC03-76SF00098. Finally, many thanks to building operations staff Fredric Smothers and Glen Starkey (Kennedy Wilson) who worked with the research team for several years.

\section{References}

[1] Hagler Bailly Consulting, Inc., Building commissioning: survey of attitudes and practices in Wisconsin, Energy Center of Wisconsin Report (1998) 172-1.

[2] M.A. Piette, B. Nordman, and S. Greenberg, Quantifying Energy Savings from Commissioning: Preliminary Results from the Pacific Northwest, Portland Energy Conservation, Inc., Proceedings of the Second National Conference on Building Commissioning (1994).

[3] Portland Energy Conservation, Inc., National Strategy for Building Commissioning, Portland Energy Conservation, Inc. (1998).

[4] D.E. Claridge, J. Haberl, M. Liu, J. Houcek, and A. Athar, Can You Achieve 150 percent of Predicted Retrofit Savings? Is It Time for Recommissioning? American Council for an Energy-Efficient Economy, Commissioning, Operations and Maintenance 5 (1994) 73-87.

[5] J. Hyvärinen, S. Kärki, Editors, Building Optimisation and Fault Diagnosis System Source Book, IEA Annex, Real Time Simulation of HVAC systems for Building Optimization, Fault detection and Diagnosis 25 (1996). 
[6] D. Behrens, K. Belfer, Commercial Customer Applications Demonstration: Open Systems Communication Architecture Project," Pacific Gas and Electric Company Research Development Report. Customer Systems File 006-96.1 December, 1996.

[7] M.A. Piette, S. Khalsa, P. Haves, P. Rumsey, K. L. Kinney, E. L. Lee, A. Sebald, C. Shockman, Performance Assessment and Adoption Processes of an Information Monitoring and Diagnostic System Prototype, prepared for the California Energy Commission, Lawrence Berkeley National Laboratory Report 44453 (1999).

[8] P. Haves, S. Khalsa, Model-based Performance Monitoring: Review of Diagnostic Methods and Chiller Case Study (forthcoming), American Council for an EnergyEfficient Economy, Commercial Buildings: Technologies, Design, and Performance Analysis 3, Lawrence Berkeley National Laboratory Report Report 45949 (2000).

[9] C. Shockman, M.A. Piette, Market Transformation and Third Party Property Managers: Routine versus Radical Technology Adoption Processes (forthcoming), American Council for an Energy-Efficient Economy, Consumer Behavior and NonEnergy Effects 8 (2000).

[10] A.S. Sebald, M. A. Piette, Diagnostics for Building Commissioning and Operations, prepared for the U.S. Department of Energy and the California Institute for Energy Efficiency, Lawrence Berkeley Laboratory Report 40512 (1997).

[11] M.A. Piette, S. Khalsa, P. Rumsey, K. L. Kinney, E. L. Lee, A. Sebald, C. Shockman, Early Results and Field Tests of an Information Monitoring and Diagnostic System for Commercial Buildings, Lawrence Berkeley National Laboratory Report 42338 (1998).

[12] Lawrence Berkeley National Laboratory, IMDS Virtual Tour and Functional Specification, http://poet.lbl.gov/tour/ (1999).

[13] Electric Eye, Electric Eye Pte Ltd, Singapore, http://www.eeye.com.sg (2001).

[14] W.J. Fisk, A. H. Rosenfeld, Estimates of improved productivity and health from better indoor environments, Indoor Air 7(3) (1997) 158-172. 